\title{
Challenging ipsilateral hip and segmental diaphyseal femur fractures with a severely osteoarthritic hip joint: lessons learnt
}

\author{
Hosam E Matar, Sadeq El-Hosh, Fahad G Attar
}

Department of Trauma \& Orthopaedics, St Helens \& Knowsley Teaching Hospitals NHS Trust, Whiston Hospital, Liverpool, Merseyside, UK

\section{Correspondence to} Hosam E Matar,

hematar@doctors.org.uk

Accepted 3 November 2015

\section{DESCRIPTION}

Patients with hip fractures very rarely have hip osteoarthritis (OA), ${ }^{12}$ with published data suggesting an inverse relationship between hip fractures and hip OA. ${ }^{3}$ In fact, hip OA is found to be protective against intracapsular fractures but increases the risk for extracapsular fractures. This is related, in part, to the restricted motion, especially rotation, abduction/adduction and flexion contractures of osteoarthritic hips, that alters the dissipation of mechanical forces generated by the fall. This leads, in turn, to increased joint reactive forces being transmitted through the femoral neck leading to increased bone density and the formation of buttressing of the medial femoral calcar. ${ }^{1-3}$

We present interesting images of a rare challenging intracapsular hip fracture and ipsilateral segmental diaphyseal femur fractures in an 82-year-old woman with severe bilateral hip OA. She suffered a fall following a right middle cerebral artery stroke with residual left hemiplaegia. Plain radiographs of the pelvis and left femur (figure 1) demonstrate the extent of her complex fractures. Following 2 weeks of medical management and optimisation, she was deemed fit for limited surgery for pain relief and to facilitate rehabilitation.

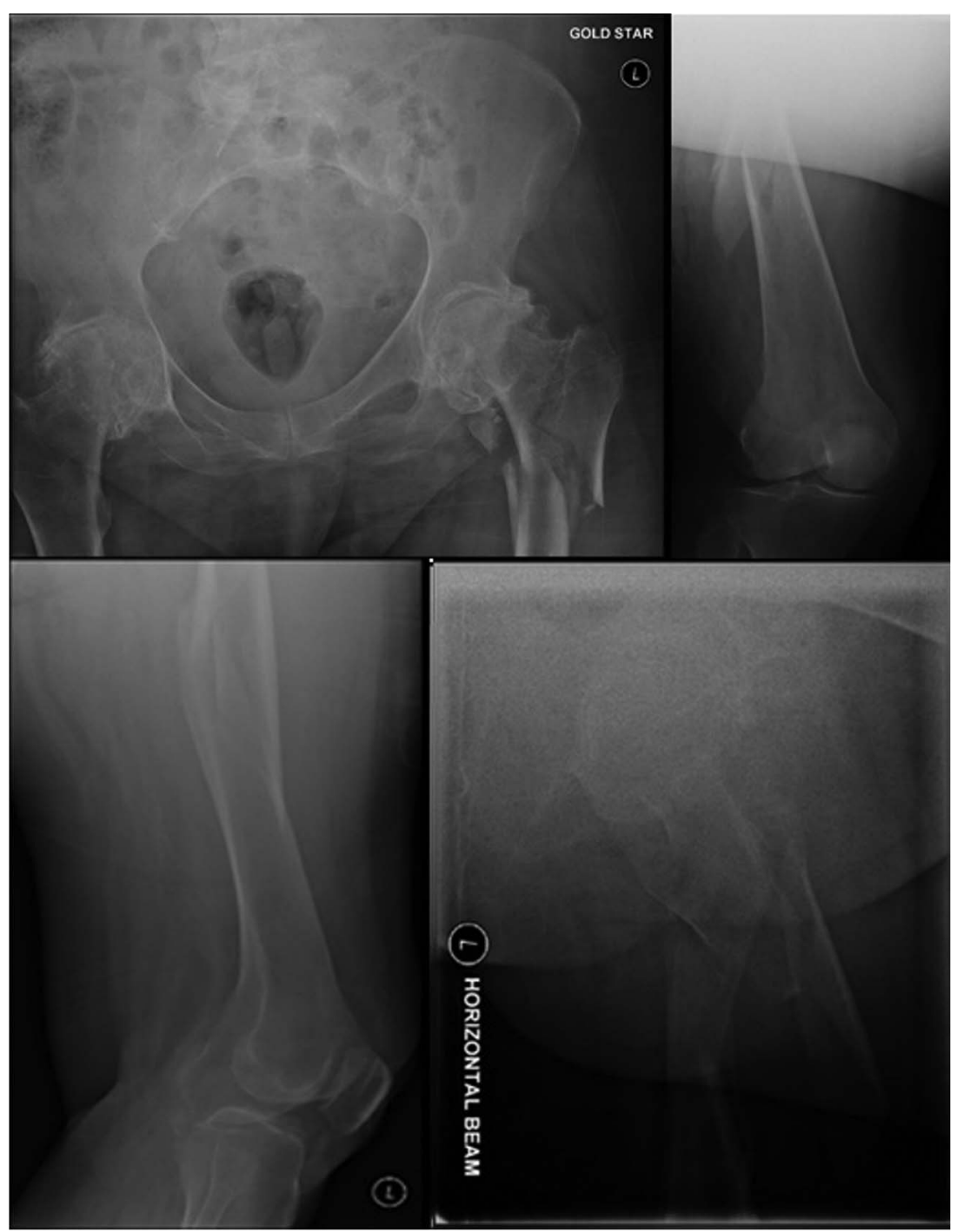

Figure 1 Plain radiographs (anteroposterior and lateral) of pelvis and left femur demonstrating a basicervical neck of femur fracture extending to the subtrochanteric region with a diaphyseal comminuted ipsilateral femoral shaft fracture. 
Figure 2 Intraoperative image intensifier demonstrating greater trochanter entry point antegrade intramedullary nailing with two proximal reconstruction screws in the femoral head (anteroposterior and lateral), supplemented by two proximal circular cables around the fracture stability. fragments, providing additional

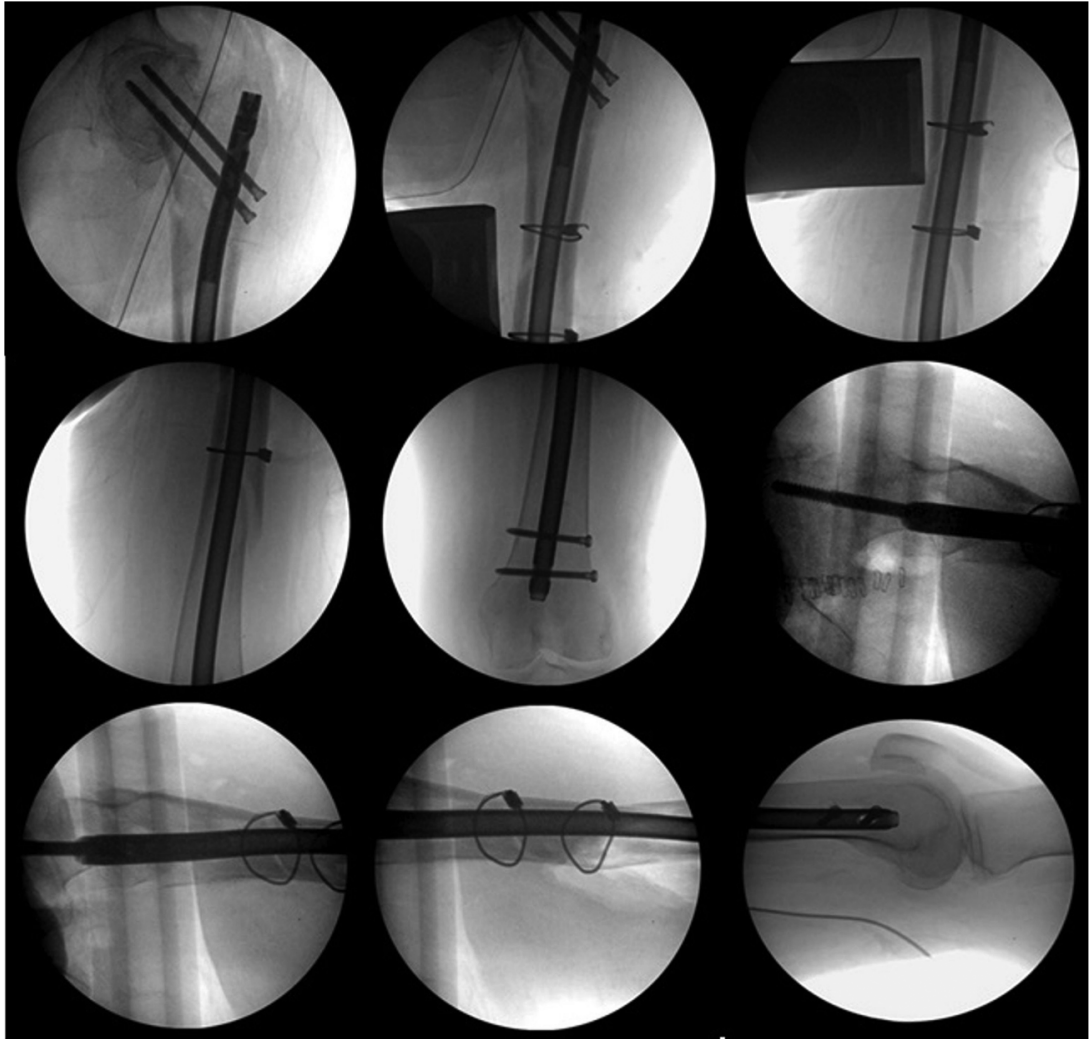

We performed a closed reduction and antegrade intramedullary fixation supplemented by extramedullary cables (figures 2 and 3) through a limited open lateral approach. The use of a 'reducer' proved invaluable in passing the guidewire through the fracture fragments. Once this was achieved, introducing a nail $(13 \mathrm{~mm})$ helped to further stabilise and reduce the
Figure 3 Postoperative plain radiographs (anteroposterior and lateral) of the pelvis and femur demonstrating a long intramedullary nailing device with two screws in the femoral head and augmented by diaphyseal cables.

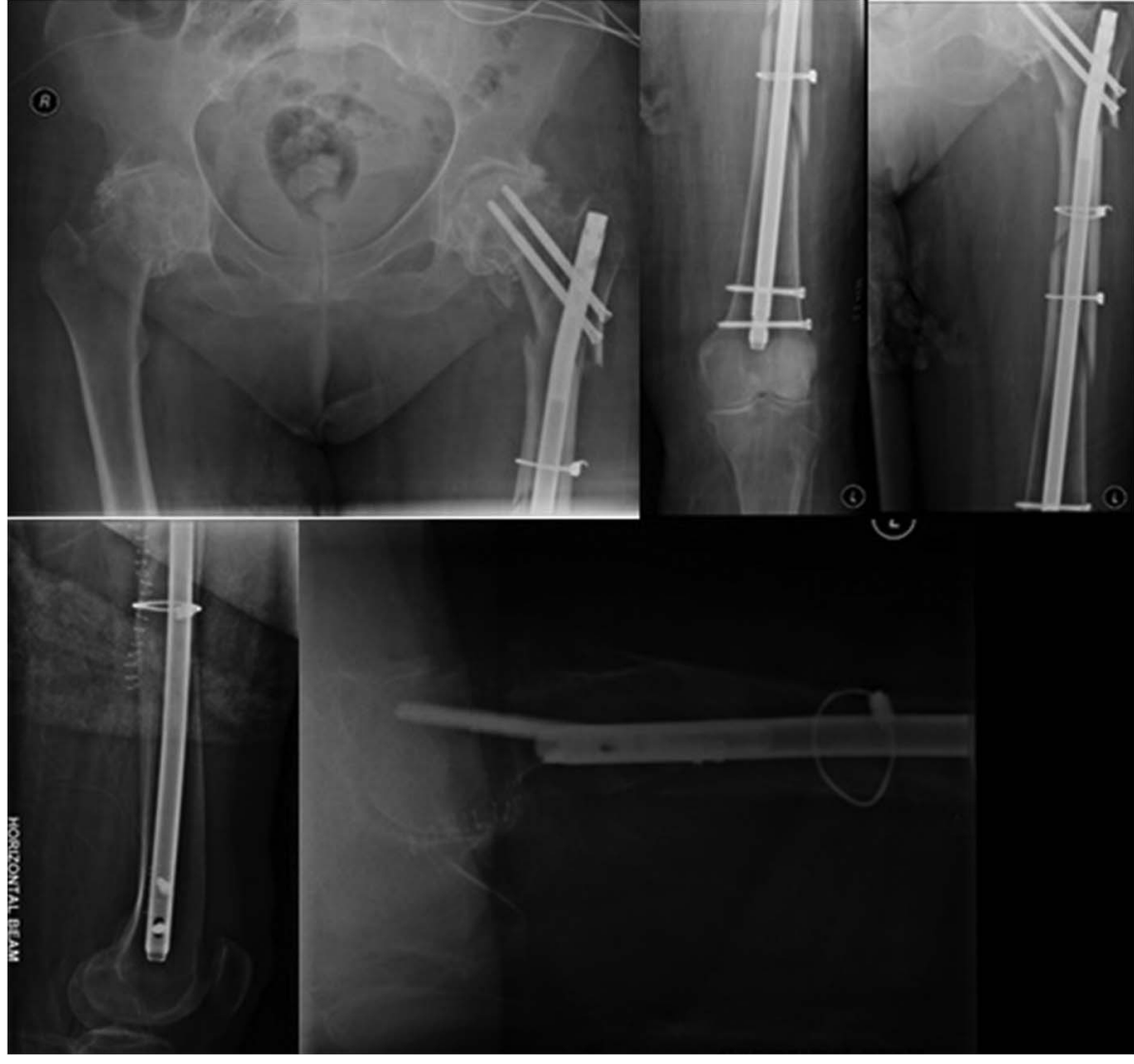

Matar HE, et al. BMJ Case Rep 2016. doi:10.1136/bcr-2015-212593 
segmental diaphyseal fragments. However, sequelae of severe OA meant fixed flexion deformity of the hip and flexed proximal fragment incarcerated by a rim of osteophytes around the

\section{Learning points}

- A suboptimal choice of surgical techniques for skeletal stabilisation might be necessary to meet the patient's needs and medical conditions.

- The use of a 'reducer', available on most nailing systems, is invaluable in achieving closed reduction of femur fractures, particularly when open reduction techniques are medically contraindicated. The reducer with its curved tip can be used with $180^{\circ}$ rotational movement to negotiate its sequential passage through the femoral canal under X-ray guidance both on anteroposterior and lateral view.

- Femoral necks in hip fractures associated with osteoarthritic hips are often incarcerated by acetabular osteophytes and not amenable to closed reduction techniques. acetabulum not amenable to closed reduction techniques. This was due to capsular contracture, particularly the fascia, over the iliopsoas and mechanical blocks due to osteophytes. Therefore, anatomical reduction could only be achieved using open techniques, and release of the contracted tissues and removal of osteophytes. A compromised anterior placement of the head screws allowed completing the procedure in closed fashion taking into account the patient's medical condition. Fortunately, our patient had an uneventful recovery and progressed satisfactorily though her rehabilitation.

Competing interests None declared.

Patient consent Obtained.

Provenance and peer review Not commissioned; externally peer reviewed.

\section{REFERENCES}

1 Dequeker J, Goris P, Uytterhoeven R. Osteoporosis and osteoarthritis (osteoarthrosis). Anthropometric distinctions. JAMA 1983;249:1448-51.

2 Wolf 0 , Ström $\mathrm{H}$, Milbrink J, et al. Differences in hip bone mineral density may explain the hip fracture pattern in osteoarthritic hips. Acta Orthop 2009;80:308-13.

3 Franklin J, Englund $\mathrm{M}$, Ingvarsson $\mathrm{T}$, et al. The association between hip fracture and hip osteoarthritis: a case-control study. BMC Musculoskelet Disord 2010;11:274.

Copyright 2016 BMJ Publishing Group. All rights reserved. For permission to reuse any of this content visit

http://group.bmj.com/group/rights-licensing/permissions.

BMJ Case Report Fellows may re-use this article for personal use and teaching without any further permission.

Become a Fellow of BMJ Case Reports today and you can:

- Submit as many cases as you like

- Enjoy fast sympathetic peer review and rapid publication of accepted articles

- Access all the published articles

- Re-use any of the published material for personal use and teaching without further permission

For information on Institutional Fellowships contact consortiasales@bmjgroup.com

Visit casereports.bmj.com for more articles like this and to become a Fellow 